\title{
MTMR \\ A CASE REPORT: POSTPRANDIAL HYPOGLYCAEMIA IN INTERMITTENT FASTING DIET FOR TYPE 2 DIABETES MELLITUS PATIENT
}

\author{
Mohd Aznan Md Aris, Syazana Aqilah Zulkifli* \\ Department of Family Medicine, Kulliyyah of Medicine, International Islamic University of Malaysia, \\ Jalan Sultan Ahmad Shah, Kuantan, Pahang, Malaysia \\ *Corresponding Author's Email:syazanaaqilah@yahoo.com
}

\begin{abstract}
This report illustrates a case of a 60-year-old lady with type 2 diabetes mellitus who performs intermittent fasting (IF) diet, with the aim to lose her weight and indirectly reverse her diabetes mellitus, hypertension, and hyperlipidaemia. She managed to get the optimum blood pressure, lose $6 \mathrm{~kg}$, and reduce her glycaemic control from $7.8 \%$ to $5.8 \%$ within 10 months period. However, she started to get episodes of symptomatic post prandial hypoglycaemia when she is about to achieve her target.
\end{abstract}

\section{Keywords: Post Prandial Hypoglycaemia; Diabetes Mellitus; Intermittent Fasting}

\section{INTRODUCTION}

Type 2 Diabetes Mellitus (T2DM) is a chronic state of hyperglycaemia from insulin resistance and low pancreatic insulin secretion secondary to pancreatic $\beta$ cell dysfunction. According to recent national survey, there are almost 2 million adult Malaysians with established T2DM, and it is estimated to be another 5 million individuals with probable prediabetes (NHMS, 2019). This growing trend urges for sustainable approaches in battling this disease in the long run. Option of therapeutic lifestyle changes especially diet improvisation is getting more promising based on the ground-breaking molecular research worldwide (Wei et al., 2017). It is also reported by Lichtash et al. (2017) that there is therapeutic benefit of intermittent fasting in a 14-month case study as an alternative treatment for type 2 diabetes mellitus. More and more encouraging evidence of intermittent fasting (IF) diet as mentioned, has cultivated a growing interest over the recent years among doctors and patients. We report on a successful case of reversing T2DM to prediabetes state in a 60year-old lady who started on IF with calorie restriction on top of standard pharmacological approach. We will also discuss about the subsequent episodic post prandial hypoglycaemia with symptoms that she had experienced.

\section{CASE STUDY}

This is a case of a 60-year-old lady with a 5-yearhistory of T2DM, hypertension and hyperlipidaemia under private general practice care. She is yet to achieve target glycaemic control with HbAlc of $7.8 \%$ and fasting blood glucose (FBS) range in between 5.1$11.3 \mathrm{mmol} / \mathrm{L}$. Her previous medications were $\mathrm{T}$. metformin $500 \mathrm{mg}$ twice daily and $\mathrm{T}$. amlodipine $5 \mathrm{mg}$ daily. Upon beginning of care at our centre, we managed the suboptimal glycaemic control by adding sulphonylurea group and increasing dose of existing antihypertension. During subsequent follow up, we noticed her fasting blood glucose started to fall together with weight loss. It has come to our attention that she has been performing intermittent fasting (IF) upon being influenced heavily social media platform. Despite knowing this practice is not a recommended approach but she would still want to give a try and started to follow time and calorie restricted diet diligently. With time, she developed episodes of hunger pangs, tremor, sweating two to three hours after eating only during daytime. The range of her blood glucose level during events were between 2.4 to $3.7 \mathrm{mmol} / \mathrm{L}$. These were reversible after taking sweets or sometimes sugar drink. She thought she would have her diabetes cured by doing IF, but at the same time, she is afraid that doctors would reject the idea of her unrecognised diet as it now has causing post prandial hypoglycaemia. On subsequent consultation, we assessed her level of understanding regarding hypoglycaemia and discussed about the crucial actions in response to it. We empowered self-monitoring blood glucose in this patient to act as quick check of the glucose status and self-motivation to allow flexibility of her chosen diet. We would expect low level of blood sugar during food restriction but surprisingly, she had post prandial hypoglycaemia instead. We advised to discontinue 
sulphonylurea agent and revised the meal selection and mealtime. As a result, we managed to prevent subsequent post prandial hypoglycaemia and overall, she had managed to lose $10 \%$ of bodyweight and achieved her target glycaemic index of HbA1c to $5.8 \%$ after 10 months of follow up.

Table 1: Timeline of patient treatment modality for type 2 diabetes and measured health parameters

\begin{tabular}{|c|c|c|c|c|c|}
\hline Note during visit & Treatment at time of visit & $\begin{array}{c}\text { HbAlc } \\
(\%)\end{array}$ & $\begin{array}{c}\text { Fasting Blood } \\
\text { Glucose } \\
(\mathrm{mmol})\end{array}$ & $\begin{array}{c}\text { Weight } \\
(\mathrm{kg})\end{array}$ & $\begin{array}{c}\text { BMI } \\
\left(\mathrm{kg} / \mathrm{m}^{2}\right)\end{array}$ \\
\hline August 2020 & $\begin{array}{c}\text { T.Metformin 500mg BD } \\
\text { T.Amlodipin 5 } 5 \mathrm{mg} \text { OD }\end{array}$ & & 8.4 & 63.3 & 26.7 \\
\hline September 2020 & $\begin{array}{c}\text { T.Metformin } 500 \mathrm{mg} \text { BD } \\
\text { T.Amlodipine 10mg OD } \\
\text { T.Gliclazide 80mg BD }\end{array}$ & & 10.8 & 63 & 24.9 \\
\hline $\begin{array}{c}\text { November 2020 } \\
\text {-patient developed reversible } \\
\text { post prandial hypoglycaemia }\end{array}$ & $\begin{array}{c}\text { T.Metformin 500mg BD } \\
\text { T.Amlodipine 10mg OD } \\
\text { off T.Gliclazide 80mg BD } \\
\text { T.A.torvastatin 20mg OD }\end{array}$ & 7.6 & 5.6 & 56 & 24.2 \\
\hline $\begin{array}{c}\text { March 2021 } \\
\text {-patient still having } \\
\text { reversible post prandial } \\
\text { hypoglycaemia }\end{array}$ & $\begin{array}{c}\text { T.Metformin 500m BD } \\
\text { T.Amlodipine 10mg OD } \\
\text { T.Atorvastatin 20mg OD }\end{array}$ & 5.9 & 6.6 & 57 & 24.0 \\
\hline $\begin{array}{c}\text { June 2021 } \\
\text {-patient is keeping well }\end{array}$ & $\begin{array}{c}\text { T.Metformin 500mg OD } \\
\text { T.Atorvastatin 20mg OD } \\
\text { T.Amlodipine 10mg OD }\end{array}$ & 5.8 & 5.9 & 58 & 24.6 \\
\hline
\end{tabular}

\section{DISCUSSION}

Lean et al., (2018) has proved that diet and lifestyle changes has now becoming the sustainable and potential modality for remission of type 2 diabetes mellitus. One of the growing interest in lifestyle changes is the practice of intermittent fasting (IF). It is a non-pharmacological approach which is evident to improve health outcome especially type 2 diabetes mellitus (Albosta \& Bakke, 2021). With this promising benefit, our patient is one of the many individuals who are fascinated by the information on the media thence experimented intermittent fasting. Considering a patient-centred approach and not to further risk our patient to do intermittent fasting unsupervised, we discuss the available evidence and possible implications related to IF (Finnell et al., 2018). Furthermore, our patient has already practiced time restriced fasting when observing Ramadhan as religious ritual without any complications to date. After many considerations, we reached the mutual decision to prepare the supervised intermittent fasting plan in achieving type 2 diabetes mellitus remission.

Intermittent fasting describes the pattern of abstinence from eating limited calorie over a specified period from 12 hours to several days, on a rotational basis(Anton et al., 2018). There are three different regimens of IF such as alternate day fasting, periodic fasting and timerestricted fasting (Anton et al., 2018). Our patient is consistently doing the most popular regimen of restricted time to eat and fast. During 16 hours of food abstinence, metabolic switch at physiological level is entirely triggered as proposed by Anton et al., (2018), thus, we anticipated hypoglycaemia event to occur. Previous literature found dysglycaemia is seen in 11 out of 768 visits among medically supervised, water-only fasting patients (Finnell et al., 2018). This was seen when glycaemic control started to improve, our patient recorded symptoms of hypoglycaemia two to three hours after meal occasionally rather than before meal. We postulate that this post prandial hypoglycaemia is due to the restoration of $\beta$ - islet cell of pancreas from intermittent fasting, that is helping to enhance second phase insulin secretion (Wei et al., 2017). Moreover, having metformin on twice daily dosage has augmented the insulin sensitivity for optimum glucose utilisation. Other than that, glucose effectiveness is reported to be the greatest contributor in glucose disposal under fasting condition (equivalent to basal insulin concentration) that may explain the improvement of the glycaemic control towards diabetes remission (Lu et al., 2020). Accompanying achieving glycaemic control, our patient managed to lose $5 \%$ of body weight from intermittent fasting.

Despite the success story in our patient, there are considerations to be made when restricting diet in post menopausal elderly to avoid macronutrient and micronutrient deficiency to cultivate healthy ageing(Fakhruddin et al., 2016). Therefore, we seek expert advices from registered dietitian to tailor diet regimen suitable for this patient. Meal replacement technique is used to provide wholesome diet whilst maintaining low glycaemic index and low calorie serving to prevent recurrent post prandial hypoglycaemia as well as to achieve total remission of diabetes in our patient.

\section{CONCLUSION}

Our case illustrates the sequalae of reversible episodic post prandial hypoglycaemia in intermittent fasting practice. This possible adverse event should be in consideration before prescribing patients to be on this therapeutic lifestyle change. Therefore, the future model of intermittent fasting needs to be supplemented with delicate multidisciplinary supervision in the setting of sufficient resource and expertise.

\section{Conflict of Interest}

We declare that there are no conflicts of interest relevant to this article. 


\section{ACKNOWLEDGEMENTS}

We are grateful and acknowledges the valuable contributions of the involved patient in giving permission to share her information. We also would like to thank the Department of Family Medicine of International Islamic University of Malaysia for technical and material support. There is no source of funding for this article writing. The informed consent has been given by patient verbally prior to manuscript writing.

\section{REFERENCES}

Albosta, M., Bakke, J. (2021). Intermittent fasting: is there a role in the treatment of diabetes? A review of the literature and guide for primary care physicians. Clinical diabetes and endocrinology, 7(1), 3 .

Anton, S. D., Moehl, K., Donahoo, W. T., Marosi, K., Lee, S. A., Mainous, A. G., 3rd, Leeuwenburgh, C., \& Mattson, M. P. (2018). Flipping the Metabolic Switch: Understanding and Applying the Health Benefits of Fasting. Obesity (Silver Spring, Md.), 26(2), 254-268.

Fakhruddin, N. N. I., Shahar, S., Aziz, N. A., Yahya, H. M., \&Rajikan, R. (2016). Which aging group prone to have inadequate nutrient intake?:TUA study ( $\mathrm{kumpulanpenuaan} \mathrm{yang} \mathrm{mana}$ lebihcenderungterhadappengambilannutrien yang tidakmencukupi?: Kajian TUA). Sains Malaysiana, 45(9), 1381-1391.

Finnell, J. S., Saul, B. C., Goldhamer, A. C., \& Myers, T. R. (2018). Is fasting safe? A chart review of adverse events during medically supervised, water-only fasting. BMC complementary and alternative medicine, 18(1), 67.

Institute for Public Health (IPH), National Institute of Health, Ministry of Health Malaysia. (2020).NCDs
- Non-Communicable Diseases: Risk Factors and other Health Problems: National Health Morbidity Survey (NHMS) 2019 Technical Report: Volume I, 26-28

Lean, M. E., Leslie, W. S., Barnes, A. C., Brosnahan, N., Thom, G., McCombie, L., Peters, C., Zhyzhneuskaya, S., Al-Mrabeh, A., Hollingsworth, K. G., Rodrigues, A. M., Rehackova, L., Adamson, A. J., Sniehotta, F. F., Mathers, J. C., Ross, H. M., Mcllvenna, Y., Stefanetti, R., Trenell, M., Welsh, P., ... Taylor, R. (2018). Primary care-led weight management for remission of type 2 diabetes (DiRECT): an open-label, cluster-randomised trial. Lancet (London, England), 391(10120), 541-551.

Lichtash, C., Fung, J., \& Ostoich, K. C., Ramos, M. (2017). Therapeutic use of intermittent fasting and ketogenic diet as an alternative treatment for type 2 diabetes in a normal weight woman: A 14month case study. BMJ Case Reports. Published.

Lu, C. H., Teng, S. W., Wu, C. Z., Hsieh, C. H., Chang, J. B., Chen, Y. L., Liang, Y. J., Hsieh, P. S., Pei, D., \& Lin, J. D. (2020). The roles of first phase, second phase insulin secretion, insulin resistance, and glucose effectiveness of having prediabetes in nonobese old Chinese women. Medicine, 99(12), e19562.

Wei, M., Brandhorst, S., Shelehchi, M., Mirzaei, H., Cheng, C. W., Budniak, J., Groshen, S., Mack, W. J., Guen, E., Di Biase, S., Cohen, P., Morgan, T. E., Dorff, T., Hong, K., Michalsen, A., Laviano, A., \& Longo, V. D. (2017). Fastingmimicking diet and markers/risk factors for aging, diabetes, cancer, and cardiovascular disease. Science translational medicine, 9(377), eaai8700. 